\title{
Growth and characterization of hydrothermally-grown zeolite crystals
}

\author{
M S JOSHI and B T BHOSKAR* \\ Department of Physics, Sardar Patel University, Vallabh Vidyanagar 388 120, India. \\ * Present address : Department of Physics, Nutan College, Sailn 431 503, Maharashtra, India.
}

MS received 22 February 1982; revised 15 June 1982

\begin{abstract}
Studies on hydrothermal synthesis of zeolite crystals, in $\mathrm{Na}_{2} \mathrm{O}-\mathrm{Al}_{2} \mathrm{O}_{3}-\mathrm{SiO}_{2}-\mathrm{H}_{2} \mathrm{O}$ system, are reported. Experimental procedure and growth parameters are briefly described. Cube-like and rod-like crystals (called VSZ-1 and VSZ-2) are illustrated. It is established that VSZ-1 crystals are metastable, while VSZ-2 crystals are stable. Crystallanity of these two samples is established. Observations and results of characterization of these two varieties by TEM, SEM, electron microprobe and infrared methods are described, illustrated and interpreted. The role of $\mathrm{Si} / \mathrm{Al}$ ratio is explained.
\end{abstract}

Keyword8. Zeolites; hydrothermal growth; crystallinity; cube-like crystal; rod-like crystal.

\section{Introduction}

Zeolites are hydrated aluminosilicates believed to have been formed under hydrothermal conditions. Many attempts have been made to produce these crystalline materials in the laboratory by methods simulating natural processes. Growth and characterization of more than 100 different types of synthetic zeolites have been reported. The present paper describes studies on growth and characterization of hydrothermally-grown zeolite crystals in the laboratory in the system $\mathrm{Na}_{2} \mathrm{O}-\mathrm{Al}_{2} \mathrm{O}_{3}-\mathrm{SiO}_{2}-\mathrm{H}_{2} \mathrm{O}$.

The work on hydrothermal alteration and synthesis of silicates has been reviewed extensively by Morey and Ingerson (1937). Synthesis of materials with chemical composition corresponding to that of analcime has been claimed by many investigators. A summary of these reports is given by Barrer (1966). Many papers containing information about kinetics and mechanism of zeolite crystallization have appeared since the review by Zhdanov (1971).

\section{Experimental details}

Starting materials used in the present investigation for crystallization of zeolites were : (i) $\mathrm{NaOH}$ pellets (SM), (ii) sodium metasilicate and (iii) sodium aluminate (Riedel). Sodium metasilicate $(2 \mathrm{~g})$, sodium aluminate $(0.5 \mathrm{~g})$ and sodium hydroxide $(0.7 \mathrm{~g})$ were mixed together and distilled water $(50 \mathrm{ml})$ was added to the mixture to form a composite sodium aluminosilicate gel. Most of the runs were carried out by preparing a sodium aluminosilicate gel at room temperature $\left(25^{\circ} \mathrm{C}\right)$, allowing it to age also at room 
temperature, for about $24 \mathrm{hr}$ and crystallizing the aged gel at an elevated temperature without stirring it. The gel was then transferred to a high pressure vessel.

In the present study, a small autoclave was used for crystallization. This vessel, specially fabricated for the purpose, consists of a solid steel cylinder $4.7 \mathrm{~cm}$ in diameter, cavity of $3.2 \mathrm{~cm}$ diameter and $9.5 \mathrm{~cm}$ depth. After transferring the gel to this vessel, more water is added (if required) until the vessel is filled two-thirds. It was then closed with a brass cap, using a copper washer and a washer of a steam packing material. This bomb was then transferred to a thermostatically-controlled muffle furnace for the required time at the required temperature. The temperature of crystallization was $160^{\circ} \mathrm{C}$, pressure 6 atm and the duration of the runs ranged from $3 \mathrm{hr}$ to 6 days. The crystals began to appear at $120^{\circ} \mathrm{C}$, and the degree of crystallinity increased as the temperature increased from 120 to $160^{\circ} \mathrm{C}$. Most of the runs were, therefore, recorded at a constant temperature of $160^{\circ} \mathrm{C}$. For trials the temperature range was from 120 to $170^{\circ} \mathrm{C}$.

\section{Observations}

Several runs were carried out for the same composition of the reactants and for the same constant temperature $\left(160^{\circ} \mathrm{C}\right)$, varying the time duration of runs. The growth period shows significant influence on the particle size, morphology and the system of the crystal. Up to a particular duration of growth, $\mathrm{Si} / \mathrm{Al}$ composition also changes. Two types of crystallites were found (i) up to $24 \mathrm{hr}$ cube-like crystals; (ii) rod-like crystals after $48 \mathrm{hr}$. The first was named VsZ-1 and the second Vsz-2.

\subsection{Characterization}

The hydrothermally-grown crystals were characterized by $\mathrm{x}$-ray powder analysis, electron microscopy and infrared studies.

\subsection{X-ray powder analysis}

$\mathrm{X}$-ray powder photographs of both varieties of crystals were taken to ascertain the state of crystallinity. $d$ values obtained from $x$-ray powder photographs given in table 1 indicate that the values in the two cases differ appreciably, showing that VSZ-1 and VSZ-2 are two distinct phases of the hydrothermally-grown zeolite crystals.

\subsection{Electron microscopy}

Electron microscopy was used extensively to study the habit and surface topography of synthetic zeolites. Intergrowth and different forms in the case of synthetic zeolites L, O and T were studied by electron microscopy (Breck et al 1968; Kerr et al 1970). Ciric (1968) studied the particle size of zeolite A, whereas the size distributions of three different batches of zeolites CaA crystals were studied by Loughlin et al (1971). Changes in the solid phase of the aluminosilicate gels, during the crystallization of the zeolite, have been studied by electron microscopy (Breck et al 1968). Recently, electron microprobe analysis of synthetic $x$-type zeolite showed that the silica to alumina molar ratio increases from the crystal centre to the exterior (Weeks et al 1977). In the present investigation electron microscope was used for the (i) electron microprobe analysis, (ii) TEM work and (iii) SEM work. 
Table 1. X-ray powder data of zeolites vsz-1 and vsz-2

\begin{tabular}{cccc}
$\begin{array}{c}\text { VSZ-1 } \\
d(\AA)\end{array}$ & $\begin{array}{c}\text { VSZ-2 } \\
d(\AA)\end{array}$ & $\begin{array}{c}\text { VSZ-1 } \\
d(\AA)\end{array}$ & $\begin{array}{c}\text { VSZ-2 } \\
d(\AA)\end{array}$ \\
\hline 7.10 & 6.0 & - & 2.00 \\
1.90 & 5.6 & 1.90 & 1.92 \\
3.85 & 5.0 & 1.80 & 1.85 \\
. & 4.8 & 1.74 & 1.70 \\
& 3.7 & 1.68 & 1.66 \\
3.30 & 3.5 & 1.58 & 1.60 \\
3.05 & 3.4 & 1.48 & 1.48 \\
2.75 & 3.0 & 1.44 & 1.47 \\
2.55 & 2.9 & 1.34 & - \\
2.40 & 2.8 & 1.32 & - \\
3.35 & - & 1.29 & - \\
3.25 & 2.0 & 1.26 & - \\
& 2.5 & 1.24 & - \\
& 2.4 & 1.21 & - \\
& 2.1 & 1.19 & - \\
\hline
\end{tabular}

Tablc 2. Silicon aluminum composition in the hydrothermally grown zeolite crystals.

\begin{tabular}{ccc} 
Growth time (hr) & Phase & Si/Al \\
\hline 0 & $\begin{array}{c}\text { Amorphous } \\
\text { aluminosilicate gel }\end{array}$ & 3.34 \\
& VSZ-1 & 3.02 \\
3 & VSZ-1 & 2.06 \\
24 & VSZ-1 & 2.05 \\
48 & VSZ-2 & 1.47 \\
\hline
\end{tabular}

3. 3a Eleuron mucroprobe analysis: Electron microprobe analysis of the samples of different hydrothermal runs was carried out, and the presence of different constituent elements ( $\mathrm{Na}, \mathrm{Si}, \mathrm{Al}$ ) confirmed. The $\mathrm{Si} / \mathrm{Al}$ ratio was computed in each case. The results are shown in table 2. It is observed that $\mathrm{Al}$ percentage in the crystals increases with time, which is accompanied by increase in Na percentage. It may be noted that $\mathrm{Si} / \mathrm{Al}$ ratio for amorphous gel is 3.34, whereas it is between 2 and 3 for VSZ- 1 and about 1.5 for VSZ-2. Thus the ratio Si/Al conclusively decides the morphology and symmetry of the crystal. Both the phases occur in the system $\mathrm{Na}_{2} \mathrm{O}-\mathrm{Al}_{2} \mathrm{O}_{3}-\mathrm{SiO}_{2}-\mathrm{H}_{2} \mathrm{O}$.

3.36 Transmission electron microscopy: Figure 1 illustrates TEM photomicrograph of the amorphous gel. synthesized VSZ-1 and VSZ-2 crystals are shown in TEM photomicrographs in figures 2 and 3 respectively. The amorphous nature of the starting aluminosilicate gel and crystallinity of VSZ-1 and VSZ-2 phases was confirmed. Figure 4 shows the presence of VSZ-2 along with VSZ-1 after $36 \mathrm{hr}$. From the TEM photomicrographs the average particle size of VSZ-1 was estimated to be about $10 \mu$, and that of VSZ-2 about $20 \mu$. These photographs reveal morphology of these two varieties, viz, cube-like for VSZ- 1 and rod-like for VSZ-2 crystals. 

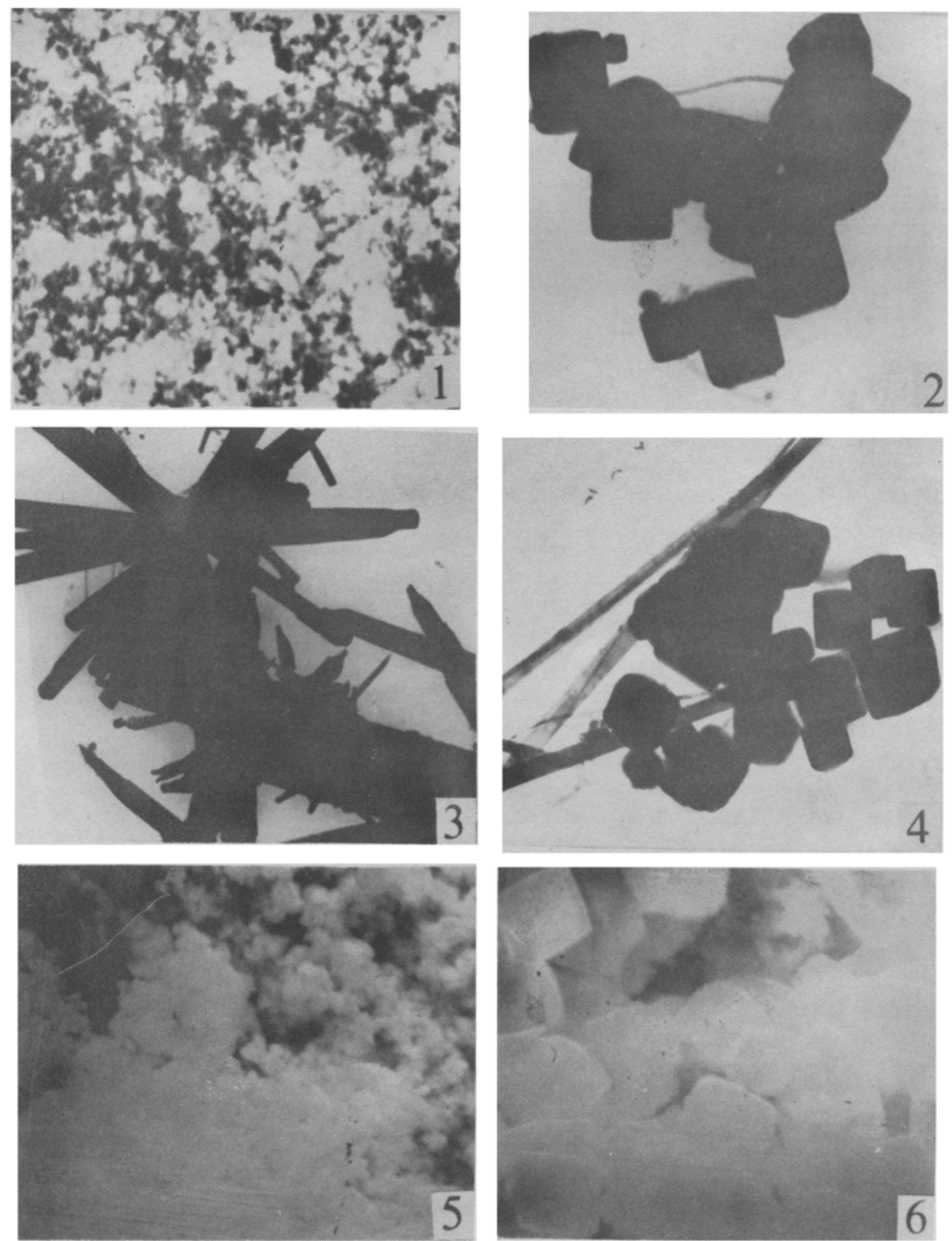

Figures 1-6. 1-4 TEM micrographs of 1. amorphous gel $\times 1600$. 2. crystals of VSZ-1 $\times$ 800. 3.Crystals of VSZ-2 $\times 1200$. 4. Mixed phase VSZ-1 and VSZ- $2 \times 800.5$ and 6 SEM micrographs of 5. Amurphous gel $\times 1800$. 6. crystals of VSZ-1 $\times 1000$. 

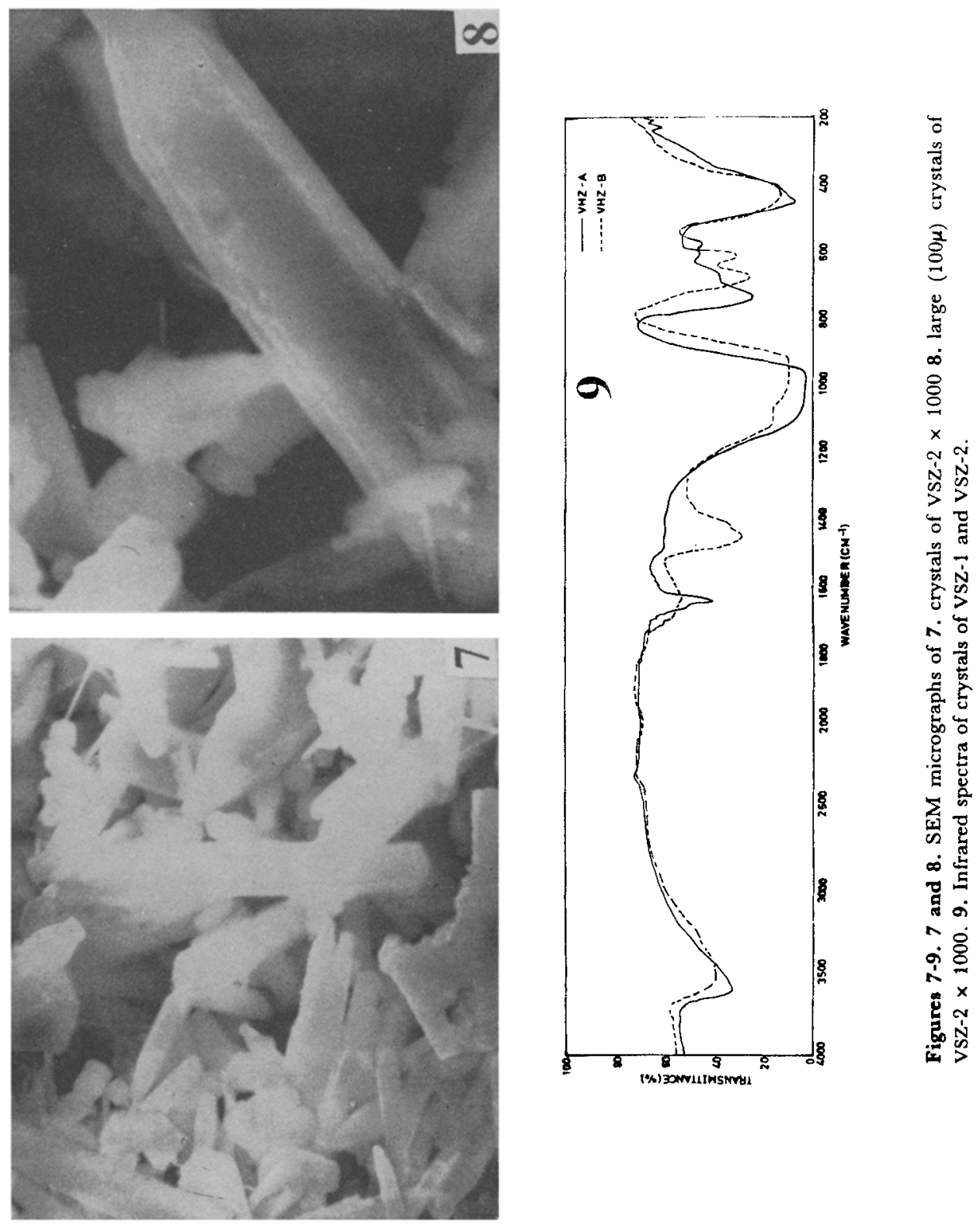
3.3c Scanning electron microscopy: Figure 5 illustrates SEM photomicrograph of the amorphous gel. VSZ-1 and VSZ-2 crystals are represented in SEM photomicrographs in figures 6 and 7 respectively. These SEM studies confirm observations and results obtained by TEM in regard to particle size and morphology of crystals of these two varieties VSZ-1 and VSZ-2. However, occasionally crystals as large as $100 \mu$ were obtained in VSZ-2 variety. One such case is illustrated by the SEM micrographs in figure 8 .

\section{Infra-red spectral studies}

Infrared spectrum in the region $4000-200 \mathrm{~cm}^{-1}$ is a sensitive tool indicating structural features of the zeolite framework. Figure 9 is a transmission infrared spectrum for Vsz-1 and VsZ-2 samples. This spectrum is obtained using $\mathrm{KBr}$ wafer technique. Here, all the bands, characteristic of zeolite framework structure, are present in both the phases. Spectral frequencies of these bands shown in table 3 indicate that not only the bands which correspond to external linkages (double rings, pore-opening etc.) but even those which correspond to internal tetrahedra are also affected. This is evident from the fact that $\mathrm{Si} / \mathrm{Al}$ composition of these two forms is different. Appearance of two bands at 215 and $235 \mathrm{~cm}^{-1}$ corresponds to pore-openings in VSZ-2, indicating that the structure becomes more open as the vsz-2 crystals grow.

\section{Discussion}

From the results obtained by $\mathrm{x}$-ray powder analysis, electron microscopy and infrared spectral studies, it is clear that the crystals VSZ-1 and VSZ-2, grown under hydrothermal conditions, are a kind of zeolite. Both the forms have grown in the system $\mathrm{Na}_{2} \mathrm{O}-\mathrm{Al}_{2} \mathrm{O}_{3}-\mathrm{SiO}_{2} \mathrm{H}_{2} \mathrm{O}$. It is believed that during the synthesis, the amorphous gel crysiallize:s to the form VSZ-1 at first $\mathrm{SiO}_{2}-\mathrm{H}_{2} \mathrm{O}$. If under identical conditions, growth time is increased, VSZ-1 changes to VSZ-2 then after. The crystals of VSZ-1 start appearing within a couple of hours after starting the run. On the other hand, crystals of VSZ-2 appear only after $36 \mathrm{hr}$ of growth period. For both the varieties all conditions of growth, except time, are identical. Thus it can be said that VSZ-1 is a metastable phase, which, as it grows, changes completely to a stable phase VSZ-2. Existence of the two different phases, VSZ-1 and VSZ-2, was confirmed by x-ray powder diffraction studies.

Table 3. Infrared spectral data of zeolites VSZ-1 and VSZ-2

\begin{tabular}{lrr}
\hline $\begin{array}{l}\text { Chaluacteristir bands of } \\
\text { leolite framework }\end{array}$ & VSZ-1 & VSZ-2 \\
\hline & & \\
\hline Pore-opening $\left(200-420 \mathrm{~cm}^{-1}\right)$ & - & 235 \\
T-O bend $\left(420-500 \mathrm{~cm}^{-1)}\right.$ & 435 & 455 \\
Double rings & 580 & - \\
$\left(500-650 \mathrm{~cm}^{-1}\right)$ & 620 & 610 \\
Symmetric stretch & 680 & 670 \\
$\left(650-820 \mathrm{~cm}^{-1}\right)$ & - & 740 \\
Assymetric stretch & 960 & 1000 \\
$\left(950-1250 \mathrm{~cm}^{-1}\right)$ & & \\
Water bands & 1450 & 1640 \\
& 3520 & 3600 \\
\hline
\end{tabular}


$\mathrm{Si} / \mathrm{Al}$ ratio plays an important role in the crystallizanon mechanism. Its value is greatc: than 3 for the amorphous gel, between 2 and 3 for the metastable phase VSz-1 and about 1.5 for VSZ-2. Since no further changes occur in composition or morphology or symmetry, on further increase in time for growth, VSZ-2 can be considered as a stable phase. The zeolite nature of VSZ-1 and VSZ-2 crystals was further confirmed by studies of their dehydration behaviour (recording DTA and TGA curves), and also ion-exchange property.

\section{Conclusions}

(i) It is possible to crystallize zeolite phases in the system $\mathrm{Na}_{2} \mathrm{O}-\mathrm{Al}_{2} \mathrm{O}_{3}-\mathrm{SiO}_{2}-\mathrm{H}_{2} \mathrm{O}$ at comparatively low temperatures, moderate pressures, and with a simple experimental set-up. (ii) Like natural zeolites, synthetic zeolites are unstable in the beginning which then change to a stable phase. (iii) Considering the influence of $\mathrm{Si} / \mathrm{Al}$ on the structure, symmetry and morphology of the crystals, it is possible to crystallize zeolites with predetermined composition. (iv) Electron microscopy can be rigorously used to study particle size, morphology, crystallinity, stages (history) of growth, and possibly symmetry of synthetic zeolite crystals. (v) Openness and consequently zeolite nature (of vsz-2) can be studied with the help of their infrared spectral studies.

\section{References}

Barrer R M 1966 Chem. Br. 29380

Breck D W and Flanigen E M 1968 Molecular steves (London Soc. of Chemical Industry) p. 47

Ciric J 1968 J. Colloid Interface Sci. 23315

Kerr I S, Gard G A, Barrer R M and Gelabova I M 1970 Am. Mineral. 55441

Loughlin K F, Darrah R I and Ruthven D M 1971 Can. J. Chem. Eng. 4966

Morey G W and Ingerson E 1937 Econ. Geol. 32607

Weeks T J (Jr) and Passoja D E 1977 Clays Clay Miner. 25211

Zhdanov S P 1971 Advance Chem. Ser. (Washington: Amer. Chemical Society) 10120 